\title{
Study on micro-phase separation structure of poly(ethylene terephthalate)-poly(hexylene terephthalate) (PET-PCT) copolymer
}

\author{
Yuan Wang, Shenglin Yang, Guang Li * \\ "State Key Laboratory for Modification of Chemical Fibers and Polymer Materials, \\ College of Material Science and Engineering, Donghua University, Shanghai; fax \\ +86-21-67792797; e-mial lig@dhu.edu.cn
}

(Received: 22 January, 2008; published: 09.10.2010)

\begin{abstract}
PET-PCT copolyesters were prepared from terephthalic acid (PTA), ethylene glycol (EG) and 1,4-cyclohexane dimethanol (CHDM) through direct esterification and the subsequent polycondensation. The chemical composition and sequence length distribution of the copolyesters were investigated by ${ }^{1} \mathrm{H}-\mathrm{NMR}$ and ${ }^{13} \mathrm{C}-\mathrm{NMR}$. The dynamic rheological behavior and dynamic mechanical property were studied by means of ARES-RFS and DMA. The results demonstrated that the obtained PET-PCT copolyesters were random block copolyesters and the content of PCT units incorporated was always greater than the feed and the numberaverage sequence length of each block in the copolyesters was in proportion to its content. The relation between storage modulus (G') and frequency (freq) deviated from linearity as the frequency (freq) tend to zero (the terminal region effect), and the frequency band where the terminal region effect appeared would shift to higher value with the increasing content of PCT, suggesting the presence of phase separations. Moreover, two glass transition temperatures were observed from DMA curves, which revealed the incompatibility of PET segments and PCT segments, i.e. the micro-phase separation took place in PET-PCT copolyesters.
\end{abstract}

\section{Introduction}

The study on structures and properties of the polymer complex system such as polymer blends, block polymers as well as liquid crystal polymers has drawn much attention recently. Based on the great number of works on their phase structures, a new field of adjusting and controlling the phase gradient of multi-component polymer systems has been developed [1]. Block polymers are long chain molecules combined from two or more parts with different chemical properties via covalent bonds. Due to the equilibrium between surface energy and conformational entropy of macromolecular chains, the micro-phase separation could take place in block polymers, resulting in complex phase morphology [2].

PET-PCT copolymers could be obtained from the polycondensation beween1,4cyclohexane dimethanol (CHDM), ethylene glycol (EG) and terephthalic acid (PTA). There has been dozens of articles covering the preparation, composition and crystallization of PET-PCT copolyesters. Turner [3] pointed out that with the increasing content of $\mathrm{CHDM}$, the melting temperature and crystallization rate would decrease within low CHDM range. Similarly, Zhai [4] et al reported that with an increasing content of CHDM, the melting point decreased while the cold crystallization temperature increased, and the glass transition temperature lay between those of pure PET and PCT. Moreover, the studies performed by Yu A F [5] 
et al revealed that PET-PCT was a typical non-Newtonican fluid exhibiting shear thinning behaviors and the melting viscosity increased with PCT content but decreased with the temperature. However, the micro-phase separation as well as the derivative properties has not gained much recognition yet.

In this article, the chemical structure and sequence lengths of the PET-PCT copolymers were determined by nuclear magnetic resonance (NMR). As the special evidence of micro-phase separation happened in the copolyesters, the dynamic rheology properties and dynamic mechanical properties were investigated by means of Advanced Rheometric Expansion System (ARES) as well as dynamic mechanical analysis (DMA), respectively.

\section{Results and discussion}

\section{Chemical Composition}

As a copolyester that have different diol components, the chemical composition of PET-PCT can be calculated from the NMR peak area ratio of $\mathrm{H}$ or $\mathrm{C}$ located in the different methylene groups of diol. On the other hand, the configuration of copolymerization can be distinguished from the different chemical shift of the quaternary carbon atoms in the phenyl ring [6]. As shown in Fig.1, there are three possible triad sequences existing in PET molecules, a h represent the types of hydrogen or carbon atoms with different chemical shift.
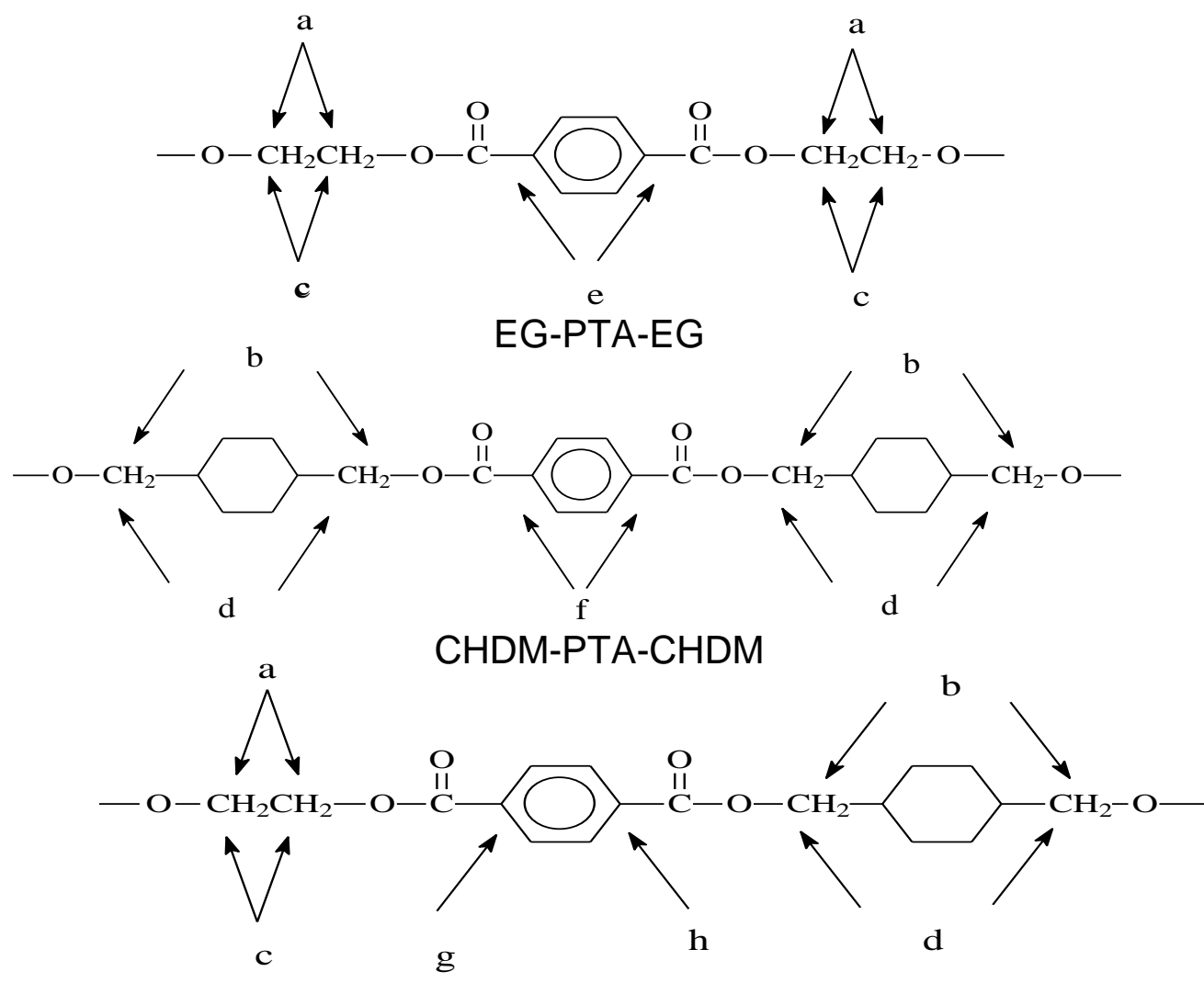

EG-PTA-CHDM

Fig. 1. Three possible sequences in PET-PCT copolymers. 
The ${ }^{1} \mathrm{H}-\mathrm{NMR}$ and ${ }^{13} \mathrm{C}-\mathrm{NMR}$ spectra of PET-PCT copolymer (PET-PCT-2) are shown in Fig 2. The peak at $4.92 \mathrm{ppm}$ (Fig. 3 (a)) should be owing to the proton in PET unit, while the peaks at $4.784 .50,4.38$ and $4.30 \mathrm{ppm}$ reflected the complexity expected for the equatorial bond and the axial bond of cyclohexyl in PCT units. $b_{\mathrm{e} 1}$ and $b_{\mathrm{e} 2}$ represented the protons in the equatorial bond whereas $b_{\mathrm{a} 1}$ and $b_{\mathrm{a} 2}$ represented the protons in axial bond. Through the integrated the peak area ratio of $a$ and $b$, we could calculate the composition ratio of PET and PCT units. In the same way, the composition calculation can also performed from the NMR data of carbon c, $d$ (trans) and $\mathrm{d}$ (cis) located at 66.2, 74.2 and $72.1 \mathrm{ppm}$. The feed composition and the actual composition determined by ${ }^{1} \mathrm{H}$-NMR and ${ }^{13} \mathrm{C}$-NMR are listed in Table 1.

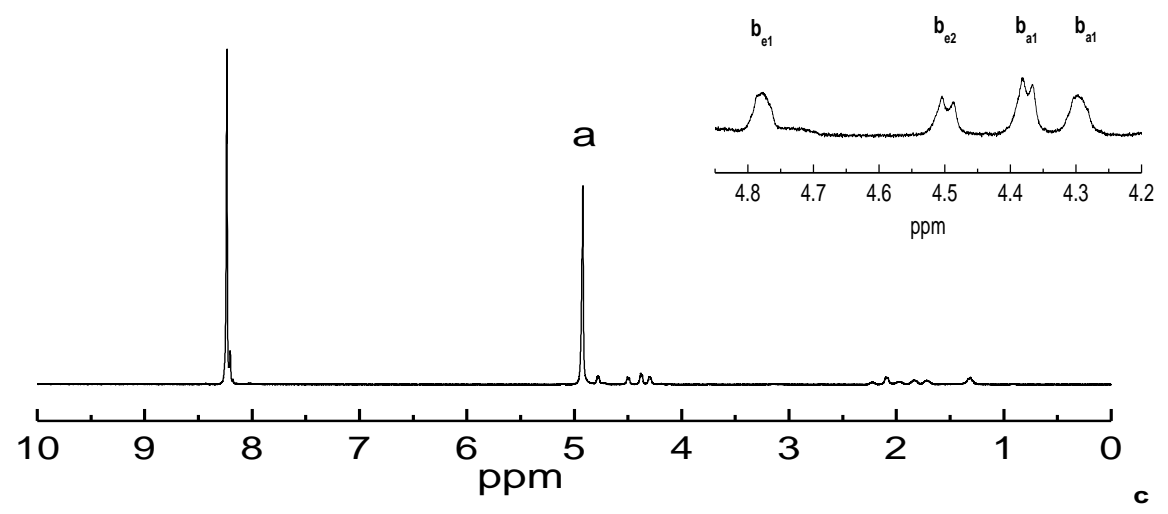

(a) ${ }^{1} \mathrm{H}-\mathrm{NMR}$

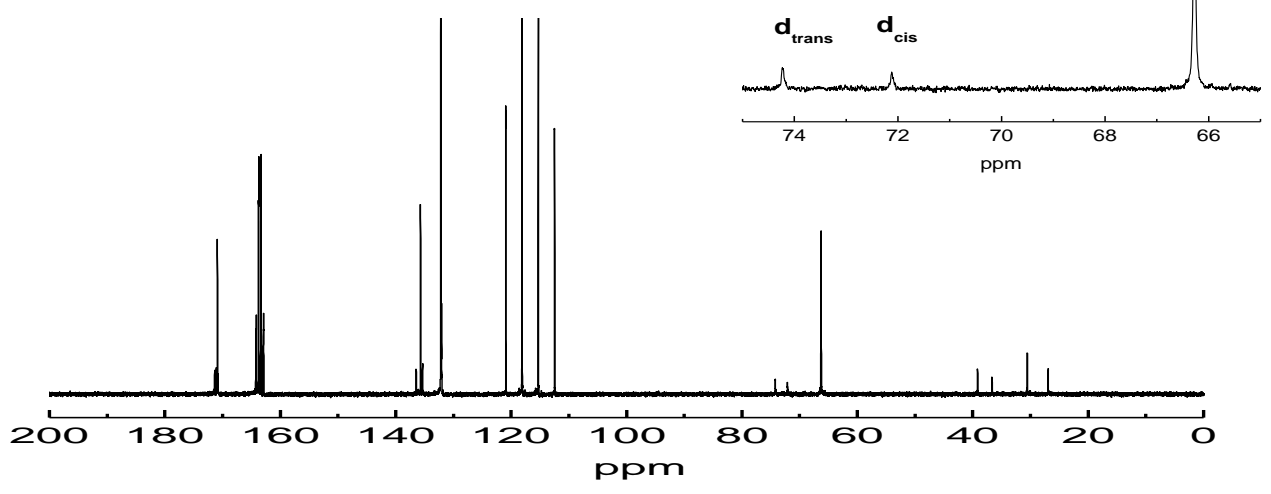

(b) ${ }^{13} \mathrm{C}-\mathrm{NMR}$

Fig. 2. NMR spectra of PET-PCT-2 copolymers.

Both ${ }^{13} \mathrm{C}$-NMR and ${ }^{1} \mathrm{H}$-NMR results showed that the mol ratio of PET units incorporated into the resultant copolymer chains were always less than the feed $\mathrm{CHDM} / \mathrm{EG}$ ratio, however, this should be owing to two reasons. Firstly, the content of PCT units is more than that in the polymerization feed. In generally, the boiling point of CHDM $\left(288{ }^{\circ} \mathrm{C}\right)$ was higher than that of EG $\left(197{ }^{\circ} \mathrm{C}\right)$, so it was difficult to vaporization during the esterification [5]. On the other hand, due to being a relatively strong nucleophile, CHDM can easily react with PTA. 
Tab. 1. Composition and intrinsic viscosity of PET-PCT copolymers.

\begin{tabular}{cccc}
\hline Sample & $\begin{array}{c}{[n]} \\
d L / g\end{array}$ & $\begin{array}{c}\text { Feed ratio } \\
(\text { EG/CHDM })\end{array}$ & $\begin{array}{c}\text { Composition in } \\
\text { polymer } \\
(\text { EG/CHDM })\end{array}$ \\
\hline PET-PCT-1 & 0.67 & $95 / 5$ & $89 / 11$ \\
PET-PCT-2 & 0.67 & $90 / 10$ & $84 / 16$ \\
PET-PCT-3 & 0.67 & $85 / 15$ & $78 / 22$ \\
\hline
\end{tabular}

a) Molar ratio of EG and CHDM monomers fed in the polymerization.

b) Measured by ${ }^{13} \mathrm{C}-\mathrm{NMR}$ Spectroscopy.

\section{Molecular sequence distribution analysis}

The configuration or the molecular sequence distribution of copolyester would have important impact on its crystallization characteristics and thermal prosperities. From the NMR shown in Fig. 3, the chemical shifts and the relative assignments of quaternary-aromatic carbon atoms for three possible triad sequences are listed in Table 2. According to the intensity of these four peaks, the number-average sequence lengths $\left(L_{n}\right)$ of the copolymers can be calculated in terms of Ya-madera's method. $\mathrm{B}=1$, the copolymer is random; when $\mathrm{B}<1$, block copolymer; $\mathrm{B} 0$, blends; $\mathrm{B} 2$, alternative copolymer [6-9].

Tab. 2. Chemical shift of quaternary aromatic carbon atoms of PET-PCT copolymers.

\begin{tabular}{ccc}
\hline The quaternary aromatic carbon & symbol & $\delta(\mathrm{ppm})$ \\
\hline EG-PTA-EG & $\mathrm{e}$ & 135.68 \\
CHDM-PTA-CHDM & $\mathrm{f}$ & 136.09 \\
EG-PTA-CHDM ( EG side ) & $\mathrm{g}$ & 136.42 \\
EG-PTA-CHDM ( CHDM side ) & $\mathrm{h}$ & 135.34 \\
\hline
\end{tabular}

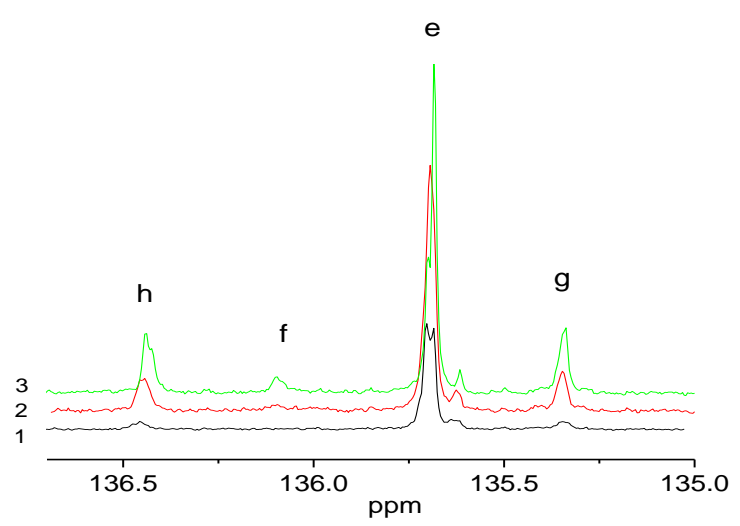

Fig. 3. The peaks of $e, f, g, h$ quaternary carbons in PET-PCT copolymers. 1. PETPCT-1, 2.PET-PCT-2, 3.PET-PCT-3). 
The mole ratio and sequence lengths, as well as the degree of randomness (B) of the PET-PCT copolymers are listed in Table 3.The B values for each the sample was less than 1 , so all the copolymers were random block copolymers. The numberaverage sequence lengths of PET and PCT units in the copolymers were in proportion to their respective composition i.e., the higher content the longer its sequence length.

Tab. 3. Sequence distributions obtained from ${ }^{13} \mathrm{C}-\mathrm{NMR}$ spectrum of PET-PCT copolymers.

\begin{tabular}{ccccc}
\hline PET-PCT copolymers & EG/CHDM & B & LPET & L $_{\text {PCT }}$ \\
\hline PET-PCT-1 & $89 / 11$ & 1.04 & 23.00 & 1.00 \\
PET-PCT-2 & $84 / 16$ & 0.81 & 12.77 & 1.36 \\
PET-PCT-3 & $78 / 22$ & 0.73 & 8.59 & 1.62 \\
\hline
\end{tabular}

Dynamic rheological properties analysis

Dynamic rheological analysis is an effective method to measure the phase structure of polymer system. Since the linear visco-elasticity response of polymer material was sensitive to the phase morphology.

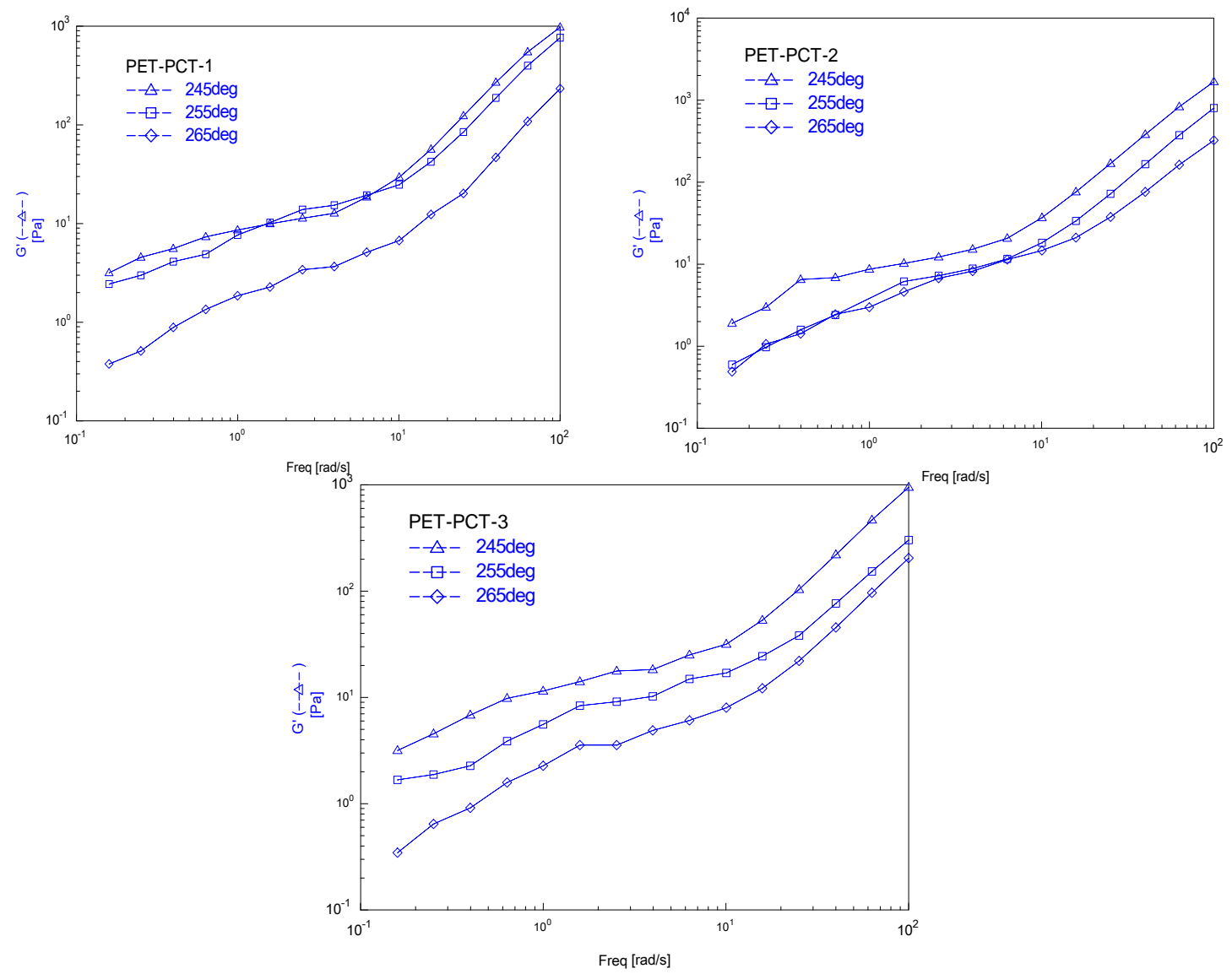

Fig. 4. Dynamic rheological curves of PET-PCT copolymers at $245^{\circ} \mathrm{C}, 255^{\circ} \mathrm{C}, 265$ ${ }^{0} \mathrm{C}$. 
Generally, within the linear strain region there was a relationship: Ig G' $\square 2 \lg$ freq, which should be tenable for most homogeneous polymer system or completely compatible polymer blends. However, the exception, i.e, the deviation from the linear relationship was named as "terminal regional effect" [10]. The occurrence of the terminal regional effect usually associated to the non-homogeneous structures. HAN [11] studied the dynamic rheological properties of PMMA and PS blends with different composition content and found that PMMA/PS (30/70) and PMMA/PS $(50 / 50)$ showed different rheological behaviours in terminal region. Concretely, the former could maintain the linear relationships, but the latter presented the terminal regional effect, indicating the phase separation had occurred in PMMA/PS (50/50) system. A study on PP samples filled with ultra-fine powered rubber particles (UFPR) under $160{ }^{\circ} \mathrm{C}$ showed that the storage modulus $\mathrm{G}$ ' deviated from linear relationship with respect to freq when the addition amount of UPFR was beyond $20 \%$. If the temperature increased to $180{ }^{\circ} \mathrm{C}$, the terminal regional effect could happen with the amount of addition up to $30 \%$ [12].

For PET-PCT copolyesters, the occurrence of terminal regional effect implied the existence of non-homogeneous structure, which meant the PET units were immiscible with the PCT units. If the number-average sequence length of PCT units increased, the phase-separated size would become larger and the terminal region effect would happen in higher frequency band. The same phenomenon has been found in PS/PVME system, the terminal regional effect of G' and G" shift to higher frequency with the increasing content of PVME [13].

\section{Dynamic mechanical analysis}

The dynamic mechanical properties of PET-PCT samples were measured in single cantilever mode. The DMA curves of copolyesters without heat treatment are shown in Fig 5, the tand curves of both PET-PCT-1 and PET-PCT-2 presented two of glass transition peaks, located at $80{ }^{\circ} \mathrm{C}$ and $120{ }^{\circ} \mathrm{C}$ corresponding to glass transition of PET phase and PCT phase respectively. As to PET-PCT-3, we failed to test the hightemperature region because the sample yielded in advance, but the change trend of glass transition still could be found.

As some originally amorphous polymers could crystallize when heated up to $T_{g}$, therefore, the storage modulus would show a increase after $\mathrm{T}_{\mathrm{g}}$ during its DMA measurement [14]. In order to understand the essence of the second transition peak, PET-PCT-1 and PET-PCT-2 were annealed at $110^{\circ} \mathrm{C}$ for $1 \mathrm{~h}$ and then met DMA test again and the curves are shown in Fig. 6. Moreover, DSC measurements had also been carried out for both untreated and annealed samples. From Fig. 7, it could be found that the annealed samples had fully crystallized, because there were no cold crystallization peaks in their DSC curves. If the second tan $\delta$ transation peak in untreated samples was associated with crystallization, the annealed samples could not give that peak. But in Fig. 6 the curves still showed two glass transition peaks though they overlapped to some extent. The detected $\mathrm{T}_{\mathrm{g}}$ 's for annealed samples were higher than those of untreated samples, which should be owing to the restriction of crystallization on the molecular movement. Therefore, the phase separation existed exactly in PET-PCT copolyesters, and the PET segments were immiscible with the PCT segments. 

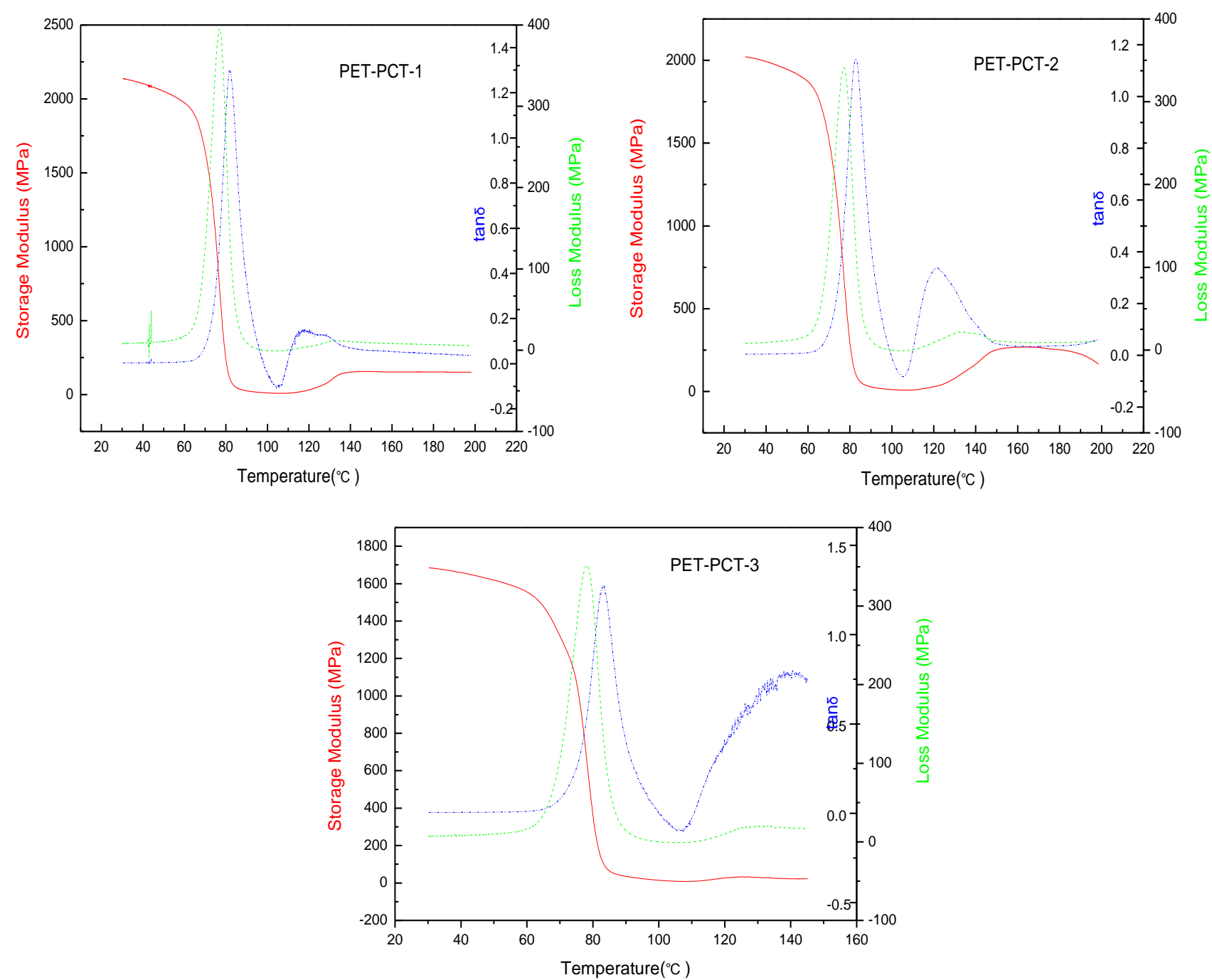

Fig. 5. DMA spectrums of PET-PCT copolymers without heat treatment.
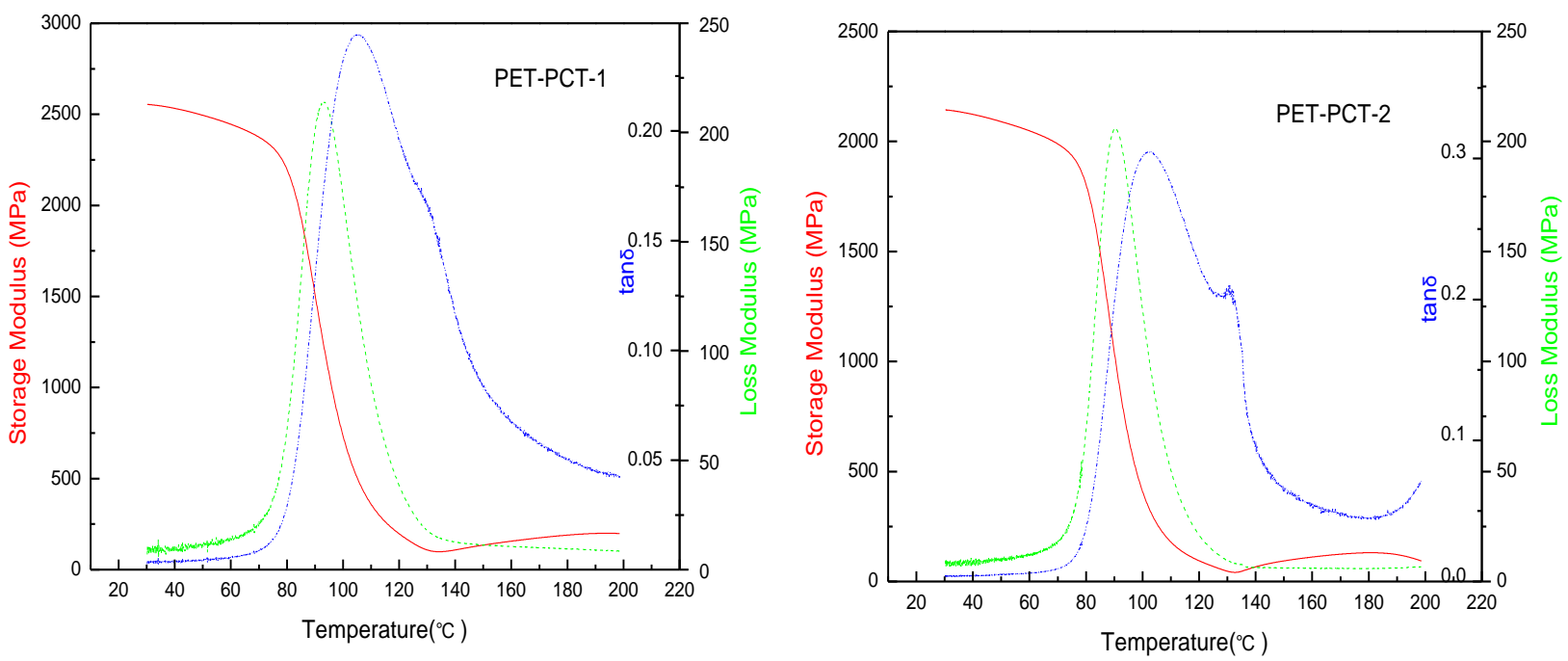

Fig. 6. DMA spectrums of PET-PCT copolymers after annealing. 


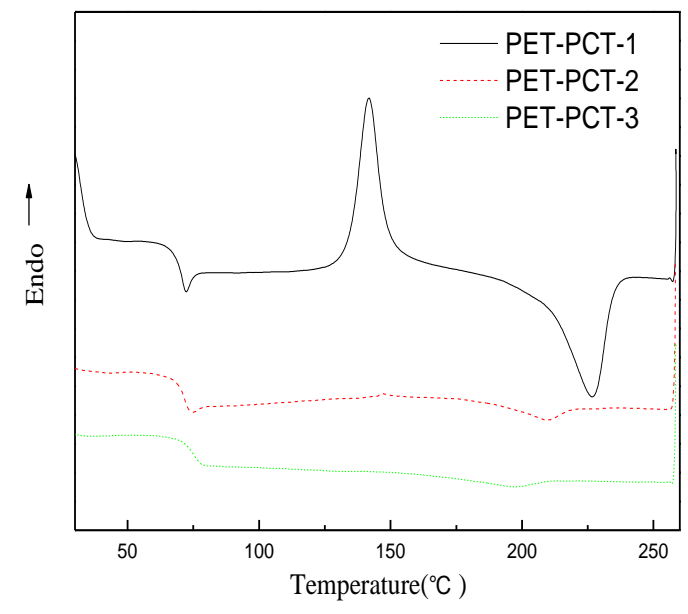

(a) samples without heat treatment

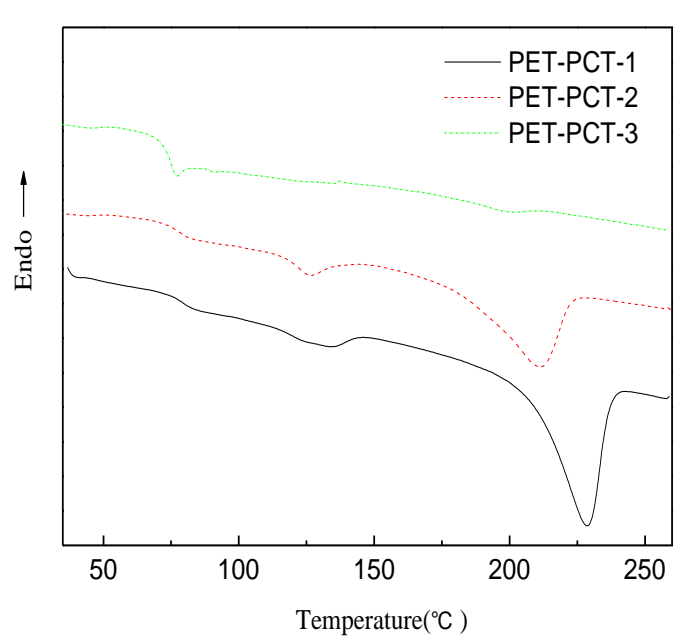

(b) annealed samples

Fig. 7. DSC curves of PET-PCT copolymers.

Tab. 5. Characteristic parameters of PET-PCT copolymers of DMA data.

\begin{tabular}{ccccc}
\hline \multirow{2}{*}{ Samples } & \multicolumn{2}{c}{ After heat treatment } & \multicolumn{2}{c}{ Before heat treatment } \\
& $\mathrm{T}_{\mathrm{g}} 1\left({ }^{\circ} \mathrm{C}\right)$ & $\mathrm{T}_{\mathrm{g}} 2\left({ }^{\circ} \mathrm{C}\right)$ & $\mathrm{T}_{\mathrm{g}} 1\left({ }^{\circ} \mathrm{C}\right)$ & $\mathrm{T}_{\mathrm{g}} 2\left({ }^{\circ} \mathrm{C}\right)$ \\
\hline PET-PCT-1 & 81.8 & 117.7 & 105.2 & 129.7 \\
PET-PCT-2 & 82.8 & 121.5 & 102.1 & 130.8 \\
PET-PCT-3 & 83.3 & - & - & - \\
\hline
\end{tabular}

\section{Conclusions}

Three PET-PCT random block copolymers with different CHDM content were prepared by the direct esterification between PTA, EG and CHDM. The composition and sequence distribution of the copolymers were investigated by NMR. The results demonstrate the content of PET units incorporated into the copolymers was always less than that in the feed ratio of EG/CHDM, the number-average sequence lengths of the block in the copolyesters were in proportion to their respective contents. The terminal region effect was observed from G'-frequency relation curves of PET-PCT copolyesters, and the terminal region began shift to higher frequency value with the incresing content of CHDM. Two glass transition peaks were observed from DMA curves even when the samples were annealed sufficiently. Therefore, it could be concluded that the micro-phase separation had happened in PET-PCT copolyesters.

\section{Experimental part}

\section{Samples preparation}

A series of PET-PCT copolymers with different compositions were synthesized from PTA, EG and CHDM by means of direct esterification technique, with $\mathrm{Sb}(\mathrm{Ac})_{3}$ as the catalyst. 
With a DACA Micro-injector, the copolymers were molded into specimens with a dimension of $17.5 \mathrm{~mm}(\mathrm{l}) \times 7.10 \mathrm{~mm}(\mathrm{w}) \times 1.15 \mathrm{~mm}(\mathrm{t})$ for ARES measurement.

\section{Measurements}

\section{-Intrinsic viscosities}

The intrinsic viscosities ([n]) of the copolymers dissolved in the phenoltetrachloroethane mixture (1:1, weight ratio) were measured with an ubbelohde viscometer at $25{ }^{\circ} \mathrm{C}$.

\section{-Nuclear Magnetic Resonance}

The chemical composition was investigated by using a NMR spectrometer (Bruker Advance $400 \mathrm{MHz}$ ), with D-trifluoroacetic acid as the solvent for both ${ }^{1} \mathrm{H}-\mathrm{NMR}$ and ${ }^{13} \mathrm{C}-\mathrm{NMR}$.

\section{-Dynamic Rheological Measurements}

The rheological measurements were performed on an Advanced Rheometric Expansion System (ARES-RFS) (TA Company) at the temperature of $245{ }^{\circ} \mathrm{C}, 255^{\circ} \mathrm{C}$ and $265{ }^{\circ} \mathrm{C}$ in nitrogen atmosphere. The parallel plate diameter was $25 \mathrm{~mm}$ and the sample gap was $1 \mathrm{~mm}$.

\section{-Dynamic Mechanical Measurements}

DMA measurements were carried out on TA- Q800 apparatus, using single cantilever mode with a heating rate of $2{ }^{\circ} \mathrm{C} /$ min from 30 to $200{ }^{\circ} \mathrm{C}$. The frequency was $1 \mathrm{~Hz}$ and the amplitude of the variations was fixed to $20 \mu \mathrm{m}$.

\section{References}

[1] He, S.G.; Xie, X.M. Plastics, 2005, 34(5): 58-61, 94.

[2] He, M.J.; Chen, W. X.; Dong, X.X. Polymer physics[M]. Shanghai, Fudan University Press, 1988.

[3] Turner, R.S. J Polym Sci Part A.Polym Chem, 2004 (23), 42, 5847.

[4] Zhai, L.P.; Du, M.; Kan, X.Z. New Chemical Materials, 2006, 36(4), 34.

[5] Yu, A F. Study on the preparation, structure and propertities ET/CT copolymer, Dissertation for academic degree of Ph.D[D]. Shanghai, Donghua University, 2004, 41.

[6] Newmark, A. J Appl Polym Sci.Polym Chem Ed, 1980(2), 18, 559.

[7] Reizo, Y.; Masao, M. J Polym Sci. Part A-1, 1967, 5(9), 2259.

[8] Li, X.G.; Huang, M.R.; Guan, G.H. Angew Makromol Chem, 1995, 227, 69.

[9] Li, X.G.; Huang, M.R.; Guan, G.H. Journal of Applied Polymer Science, 1997, 66(11), 2129.

[10] Zheng, Q.; Zhao, T.J. Chinese Journal of Materials Research 1998, 12(3), 225.

[11] Han, J.H.; Chin, C.F.; Han, C.D. et al. Polymer, 1995, 36(12), 2451.

[12] Zheng, Q.; Yan, X.C.; Miao, D. Chinese Journal of polymer science, 2004, 22(4), 363.

[13] Brekner, M.; Cantow, H.; Schneider, H. et al. Polym Bull, 1985, 14(1), 17.

[14] Guo, M L. Dynamic mechnical themo-analysis of polymer and composite material Beijing, Press of the Chemical Industry, 2002. 